\title{
Reflexões sobre a atuação dos assistentes sociais e psicólogos junto à metodologia do Depoimento sem Dano
}

\author{
Reflections on the role of Social Workers and \\ Psychologists in relation to the methodology of \\ Testimony without Harm
}

\author{
Daniella Borges Ribeiro* \\ Natany Bonadiman** \\ Stefanne Gomes Gonçalves ${ }^{* * *}$ \\ Wanderléia das Dores Rassele ${ }^{* \star * *}$
}

\begin{abstract}
Resumo: Este estudo tem como objetivo apresentar um debate sobre a atuação dos assistentes sociais e psicólogos junto à metodologia do Depoimento sem Dano. Para a realização do estudo, recorremos a um levantamento bibliográfico e documental sobre o tema e, a partir de contatos realizados nos Conselhos Regionais de Serviço Social e Psicologia do Estado do Espírito Santo, selecionamos oito profissionais, sendo: dois juízes, um advogado, um psicólogo e quatro assistentes sociais. Os oito profissionais selecionados participaram de uma pesquisa que se realizou por meio de entrevistas e questionários. A partir da análise dos dados, foi possível verificar algumas polêmicas no que se refere à posição dos Conselhos Federais de Serviço Social e Psicologia, além do desvirtuamento do conceito de Proteção Integral previsto pelo Estatuto da Criança e do Adolescente.
\end{abstract}

Palavras-chave: Depoimento sem dano. Criança. Adolescente.

\begin{abstract}
This study aims to present a debate on the role of Social Workers and Psychologists in relation to the methodology of Testimony without Harm. To conduct the study, we undertook a bibliographic and document search on the subject and selected, from contacts made in the Regional Councils of Social Work and Psychology in the state of Espírito Santo, eight professionals, as follows: two judges, a lawyer, a psychologist and four social workers. The eight selected professionals participated in a survey constituted of interviews and questionnaires. From the analysis of the data it was possible to verify some controversies regarding the position of the Federal Councils of Social Work and Psychology and the distortion of the concept of Integral Protection provided by the Child and Adolescent Statutes.
\end{abstract}

Keywords: Testimony without harm. Child. Adolescent.

Recebido em: 11/12/2011. Aceito em: 12/06/2012.

\footnotetext{
* Doutoranda do Programa de Pós-Graduação em Política Social pela Universidade Federal do Espírito Santo (UFES). Mestre em Política Social pela UFES. Graduada em Serviço Social pela UFES. Vitória, Espírito Santo, Brasil. E-mail: dborgesribeiro@yahoo.com.br

** Graduada em Serviço Social pela Faculdade Novo Milênio. Vila Velha, Espírito Santo, Brasil. E-mail: natylorenzoni@hotmail.com

*** Graduada em Serviço Social pela Faculdade Novo Milênio. Vila Velha, Espírito Santo, Brasil. E-mail: stefannyye@hotmail.com

**** Graduada em Serviço Social pela Faculdade Novo Milênio. Vila Velha, Espírito Santo, Brasil. E-mail: leiarassele@hotmail.com
} 


\section{Introdução}

Sabe-se que o Brasil incorporou um posicionamento europeu e profundamente conservador no trato com as crianças e os adolescentes. Desde o início de sua história, é possível verificar certa desvalorização desse público, tanto que, no período do desbravamento e da colonização, eram muito comuns o abandono de crianças e o infanticídio (LEITE, 1999).

Ao longo dos anos, a aplicação de diversos castigos, o trabalho forçado e as péssimas condições de vida configuraram características marcantes das ações direcionadas à infância e à adolescência em nosso país. Dada essa situação, no decorrer do tempo foram surgindo diversas reivindicações no que tange ao reconhecimento e à implementação dos direitos das crianças e adolescentes no Brasil (RIZZINI; RIZZINI, 2004).

A partir de diversas lutas sociais, emergiu em 1988 a atual Constituição Federal Brasileira. Nela, foram assegurados direitos a amplos setores da sociedade. Com relação à criança e ao adolescente, o Artigo 227 preceitua que:

É dever da família, da sociedade e do Estado assegurar à criança e ao adolescente, com prioridade absoluta, o direito à vida, à saúde, à alimentação, à educação, ao lazer, à profissionalização, à cultura, à dignidade, ao respeito, à liberdade e à convivência familiar e comunitária, além de colocá-lo a salvo de toda forma de negligência, discriminação, exploração, violência, crueldade e opressão (BRASIL, 1988).

Para a regulamentação desse artigo, foi aprovado em 1990 o Estatuto da Criança e do Adolescente (ECA). O ECA determina que o direito à vida, à saúde, à liberdade, ao respeito, à dignidade, à convivência familiar e comunitária, à educação, à cultura, ao esporte, ao lazer, à profissionalização e à proteção ao trabalho é fundamental para todas as crianças e adolescentes, o que denota que sua realização não pode prescindir de uma ação efetiva do Estado na formulação das políticas públicas (CARVALHO, 2000). O Artigo $5^{\circ}$ também aponta: "Nenhuma criança ou adolescente será objeto de qualquer forma de negligência, discriminação, exploração, violência, crueldade e opressão, punido na forma da lei qualquer atentado, por ação ou omissão, aos seus direitos fundamentais" (BRASIL, 1990).
Nessa óptica, diversas estratégias têm sido formuladas para o enfrentamento da violência contra esse público, o que constitui uma das maiores preocupações nos tempos atuais. $\mathrm{E}$, dentre os assuntos mais contemporâneos, destaca-se a discussão sobre a metodologia do Depoimento sem Dano (DSD). ${ }^{1}$

A metodologia do DSD foi criada como uma estratégia para inquirir crianças e adolescentes em situação de violência sexual ou que testemunharam esse tipo de violência. No Brasil, ela foi implementada de forma pioneira em maio de 2003, na Vara da Infância e Juventude de Porto Alegre/RS, e teve como técnica responsável pela inquirição uma psicóloga (CEZAR, 2007).

Nesse cenário de implementação de uma nova metodologia para o trato desses casos, fortaleceu-se o debate sobre a garantia dos direitos das crianças e dos adolescentes. Note-se que essa metodologia tem sido vista de forma polêmica: ora como inovadora e necessária, ora como nociva ao exercício dos direitos desse público. Mas é preciso salientar que a procura por métodos alternativos para a tomada de depoimentos vem ocorrendo em todo o mundo (CEZAR, 2007; BRITO, 2008).

\footnotetext{
1 Esse tipo de metodologia possui diversas terminologias, que variam de acordo com o país e as concepções adotadas. Alguns nomes utilizados são: entrevista forense em Câmara de Gesell; depoimento especial; inquirição especial e entrevistas para evidências gravadas em videotape (SANTOS, GONÇALVES, 2008).
} 


\section{Práticas alternativas para a tomada de depoimento de crianças e adolescentes}

A violência sexual ${ }^{2}$ praticada contra a criança e o adolescente geralmente não vem acompanhada de vestígios físicos, acarretando para o Sistema de Justiça inúmeras dificuldades para desvendar os comunicados e as ocorrências que chegam aos diferentes órgãos, como, por exemplo, o Conselho Tutelar (AZAMBUJA, 2009).

Dessa forma, a criança e o adolescente nessa situação frequentemente recorrem ao silêncio - seja por medo de represálias, pelo desconhecimento sobre o relacionamento sexual, por vergonha, pelo sentimento de culpa, pelo fato de nutrir um afeto pelo abusador, por medo de ser desacreditada, dentre outros motivos (ROZANSKI, 2003).

Em algumas ocasiões, a palavra dos que são submetidos à violência sexual não possui veracidade diante dos adultos e suas fragilidades motivam os abusadores a prosseguir com a violação. Além disso, os crimes muitas vezes permanecem impunes, favorecendo a reincidência (FALEIROS, 2003).

Em muitos casos de violência sexual, crianças e adolescentes são chamados a depor. Contudo, muitos demonstram receio em relação à realização de tal ato e possuem pouca compreensão sobre o processo judicial, o que pode aumentar sua ansiedade. Em alguns países, os

\footnotetext{
${ }^{2}$ A violência (ou abuso) sexual pode ser entendida como "todo ato ou jogo sexual, relação heterossexual ou homossexual cujo agressor esteja em estágio de desenvolvimento psicossexual mais adiantado que a criança ou o adolescente. Tem por intenção estimulá-la sexualmente ou utilizá-la para obter satisfação sexual. Essas práticas eróticas e sexuais são impostas à criança ou ao adolescente pela violência física, por ameaças ou indução de sua vontade. Podem variar desde atos em que não existam contato sexual (voyeurismo, exibicionismo), até os diferentes tipos de atos com contato sexual sem penetração (sexo oral, intercurso interfemural) ou com penetração (digital, com objetos, intercurso genital ou anal). Engloba ainda a situação de exploração sexual visando lucros como prostituição e pornografia. [...] Os agentes agressores mais frequentes são os pais, padrastos, parentes ou pessoa que tem proximidade com a criança e o adolescente abusado. Podem ser vizinhos ou outras pessoas que exerçam alguma influência sobre ela ou desfrutam da confiança de seus pais e parentes. Por vezes, o agressor é um adolescente. A mãe muito raramente aparece como agressora nesse tipo de abuso, mas é comum sua participação 'passiva', 'consentindo' silenciosamente, constrangida pelo medo da desestruturação da unidade familia ou por temor às ameaças do seu cônjuge" (DESLANDES, 1994, p. 17).
}

menores de 14 anos são poupados e raramente comparecem ao tribunal durante audiências ou julgamentos. Em Israel, por exemplo, o profissional entrevistador depõe no lugar dos menores de idade e relata o que eles dizem. Já na Inglaterra, a promotoria de justiça apresenta o vídeo da entrevista ao tribunal (GOODMAN, 2008).

Nos Estados Unidos, a Emenda 6 à Constituição Federal exige que a criança, assim como os adultos, preste testemunho ao vivo no tribunal (apesar de a criança não ser obrigada a testemunhar em audiências anteriores ao julgamento). Se o caso for a julgamento e ela for considerada testemunha-chave, é muito provável que tenha de comparecer e testemunhar na presença do acusado e ser submetida à acareação nas salas de julgamento abertas. Esse processo pode trazer vários danos emocionais, e, por esse motivo, algumas ações são realizadas com vistas a diminuir os danos sofridos (GOODMAN, 2008). ${ }^{3}$

Muitos estudos demonstram certa preocupação quanto ao depoimento de crianças e adolescentes, alegando, principalmente, que esse processo traz grande sofrimento e revitimiza os envolvidos. Entretanto, há pesquisadores que apontam para a importância do comparecimento ao tribunal, como uma experiência fortalecedora - se a criança ou o adolescente envolvido for tratado com respeito e tiver à sua disposição estratégias de apoio e proteção. Para alguns estudiosos, o problema não está no depoimento e sim na forma como os tribunais, os profissionais da área jurídica e a família lidam com as necessidades emocionais da vítima ${ }^{4}$ antes, durante e depois de seu comparecimento ao tribunal (GOODMAN, 2008).

Nesse sentido, muitas estratégias têm sido desenvolvidas com o objetivo de ouvir a criança ou adolescente, buscando assegurar a justiça e reduzir a revitimização. As práticas alternativas de tomada de depoimento desse público são muito recentes na história, sendo que as mais antigas datam de $1985 .{ }^{5}$ É interessante observar que os países pioneiros iniciaram a busca de

\footnotetext{
${ }^{3}$ Para maiores informações sobre o assunto, consultar a referência indicada.

${ }^{4}$ Aqui, o termo "vítima" não sinaliza uma posição passiva da pessoa envolvida, mas sim quem foi o alvo da agressão.

${ }^{5}$ Foram implantadas nesse ano nos Estados Unidos e Israel.
} 
métodos alternativos antes mesmo da aprovação da Convenção Internacional sobre os Direitos da Criança (SANTOS; GONÇALVES, 2008).

Em pesquisa recente, verificou-se a existência de práticas alternativas de tomada de depoimentos de crianças e adolescentes em 25 países dos cinco continentes geográficos, conforme o Quadro $1^{6}$.
Segundo Santos e Gonçalves (2008), $60 \%$ dos 25 países citados estão ancorados em marcos legais que normatizam o depoimento especial e existe uma legislação específica para tal fim (ver Quadro 2).

Quadro 1 - Países onde existem práticas alternativas de tomada de depoimento

\begin{tabular}{|c|c|}
\hline Continentes & $\begin{array}{c}\text { Países onde existem práticas alternativas de tomada de } \\
\text { depoimento }\end{array}$ \\
\hline América do Sul & $\begin{array}{r}\text { Argentina (2004), Brasil (2003), Chile (2003), Colômbia (2008), } \\
\text { Equador (2008), Paraguai (2008) e Peru (2008). }\end{array}$ \\
\hline Europa & $\begin{array}{r}\text { Espanha (2000), Escócia (2004), França (2000), Inglaterra (1991), } \\
\text { Lituânia (2004), Noruega (2004) e Suécia (2008). }\end{array}$ \\
\hline Ásia & Índia (2003), Israel (1985), Jordânia (2003) e Malásia (2002). \\
\hline América Central e Caribe & Costa Rica (2006) e Cuba (2005). \\
\hline América do Norte & Canadá (2004) e Estados Unidos (1985). \\
\hline Oceania & Austrália (1999) e Nova Zelândia (2006). \\
\hline África & África do Sul (1991). \\
\hline
\end{tabular}

Fonte: Santos e Gonçalves, 2008.

Quadro 2 - Legislações sobre a tomada de depoimento de crianças e/ou adolescentes

\begin{tabular}{|c|c|}
\hline $\begin{array}{c}\text { Países em que a lei especifica a proteção } \\
\text { de crianças e adolescentes testemunhas em } \\
\text { processos judiciais. }\end{array}$ & $\begin{array}{c}\text { África do Sul, Argentina, Austrália, Costa Rica, Estados } \\
\text { Unidos (Califórnia), França, Índia, Israel, Inglaterra, } \\
\text { Jordânia, Lituânia, Malásia, Nova Zelândia, Noruega e } \\
\text { Suécia. }\end{array}$ \\
\hline $\begin{array}{c}\text { Países em que a produção antecipada de } \\
\text { provas é garantida pelo Código Penal (para } \\
\text { todos os cidadãos). }\end{array}$ & Brasil, Colômbia, Chile, Equador, Paraguai e Peru. \\
\hline $\begin{array}{c}\text { Países em que a lei destina-se a } \\
\text { testemunhas vulneráveis sem especificar a } \\
\text { proteção de criança e/ou adolescente. }\end{array}$ & Canadá, Cuba, Espanha e Escócia. \\
\hline
\end{tabular}

Fonte: Santos e Gonçalves, 2008.

\footnotetext{
${ }^{6}$ Ao lado do nome do país, está o ano de implantação das experiências de tomada de depoimento.
} 
Diante do exposto, constata-se que as legislações de vários países do mundo vêm sofrendo alterações para assegurar a implementação do Artigo 12 da Convenção Internacional sobre os Direitos da Criança de 1989, que estabelece:

§1. Os Estados Membros assegurarão à criança que for capaz de formar seus próprios pontos de vista, o direito de exprimir suas opiniões livremente sobre todas as matérias atinentes à criança, levando-se devidamente em conta essas opiniões em função da idade e maturidade da criança.

§2. Para esse fim, à criança será, em particular, dada a oportunidade de ser ouvida em qualquer procedimento judicial ou administrativo que Ihe diga respeito, diretamente ou através de um representante ou órgão apropriado, em conformidade com as regras processuais do direito nacional (ONU, 1989, grifo nosso).

Contudo, profissionais que são contrários à inquirição de crianças e adolescentes apontam que, de acordo com a Convenção Internacional, a criança tem o direito de ser ouvida, o que não significa que ela será inquirida. Ou seja, a possibilidade de inquirição não significa a obrigatoriedade desta (BRITO, 2008). Mas é importante destacar que, mesmo ocorrendo essa polêmica, alguns países têm construído leis específicas para o trato da questão (SANTOS; GONÇALVES, 2008).

De acordo com Santos e Gonçalves (2008), as legislações que normatizam a tomada especial de depoimento definem os métodos e as técnicas que devem ser utilizados de modo a assegurar todas as condições ambientais e cognitivas para a realização da oitiva desse público. Os métodos e as técnicas estabelecidos por lei para a tomada do depoimento especial se dividem entre a entrevista em CCTV $^{7}$ e uso de
Câmara Gesell ${ }^{8}$.

Dos 25 países estudados por Santos e Gonçalves (2008), a maioria (40\%) estabeleceu que a oitiva da criança e do adolescente deve ser realizada pela polícia, no primeiro momento, e, caso o processo vá a julgamento, a testemunha deve ser ouvida pelo juiz, pelo promotor e pelo defensor, podendo haver a participação de outros técnicos, como um assistente social. Nos outros países, são diversos os profissionais designados para tais atividades, conforme se vê no Quadro 3.

\footnotetext{
${ }^{8}$ A Câmara Gesell foi criada pelo psicólogo norte-americano Arnold Gesell para o estudo das etapas do desenvolvimento infantil. Ela é constituída por duas salas divididas por um espelho unidirecional que permite visualizar a partir de um lado o que acontece no outro, mas não vice-versa. Essa Câmara passou a ser utilizada para a tomada de depoimento de crianças e adolescentes vítimas ou testemunhas de violência sexual. Nesse ambiente, crianças e adolescentes são ouvidos por profissionais - estes devem empregar uma escuta especializada, que conta com diversos equipamentos eletrônicos (SANTOS; GONÇALVES, 2008).
}

${ }^{7}$ O CCTV (Closed Circuit of Television) é o sistema mais utilizad evita o contato de crianças ou adolescentes com o grande pútais indivíduos têm de testemunhar em sala aberta de tribuna. Nessa modalidade de tomada de depoimento, o depoente, que seja testemunha ou vítima, poderá se beneficiar da presença de essoa para acompanhá-lo enquanto presta seu testem GONÇALVES, 2008) 
Quadro 3 - Profissionais responsáveis pela tomada de depoimento em diversos países

\begin{tabular}{|c|c|}
\hline Profissionais responsáveis pela ação & Países \\
\hline $\begin{array}{c}\text { Polícia no primeiro momento; juiz, promotor e } \\
\text { defensor, se for a julgamento; outros }\end{array}$ & $\begin{array}{c}\text { África do Sul, Austrália, Israel, Inglaterra, Malásia, } \\
\text { Noruega, Nova Zelândia, Índia, Jordânia e Suécia. }\end{array}$ \\
\hline Psicólogo & $\begin{array}{c}\text { Argentina, Colômbia, Equador, Paraguai, Peru e } \\
\text { Chile }\end{array}$ \\
\hline Policial, médico, psicólogo e assistente social & Canadá e França \\
\hline Psicólogo e assistente social & Brasil \\
\hline Psicólogo ou psiquiatra & Costa Rica \\
\hline $\begin{array}{c}\text { Psicólogo, psicopedagogo, promotor, defensor do } \\
\text { imputado, diretor da área de infância e adolescência } \\
\text { do Ministério do Interior e juiz (não é usual) }\end{array}$ & Lituânia \\
\hline Promotor, juiz e psicólogo & Espanha \\
\hline $\begin{array}{c}\text { Juiz de instrução, promotor, defensor do imputado, } \\
\text { defensor da criança e adolescente, técnico em } \\
\text { documentação }\end{array}$ & Escócia \\
\hline $\begin{array}{c}\text { Juiz, detetive policial e assistente social } \\
\text { Profissional responsável pela investigação, } \\
\text { advogado do Departamento de Advocacia Distrital e } \\
\text { assistente social (não é usual) }\end{array}$ & Estados Unidos \\
\hline
\end{tabular}

Fonte: Santos e Gonçalves, 2008.

\section{O surgimento da metodologia do Depoimento Sem Dano no Brasil}

Segundo Fávero (2008), no Brasil, toda fase processual que envolve crimes deve ser embasada por preceitos da Constituição Federal de 1988 que dizem respeito ao "devido processo legal, ampla defesa e o contraditório". A assistente social explica que, nesse sentido, o Código de Processo Penal Brasileiro (1941) disciplina a aplicação da Legislação Penal em relação à prática de crimes, inclusive crimes que envolvam a violência sexual contra crianças e adolescentes. O processo é estabelecido da seguinte forma:

a) denúncia oferecida pelo promotor de justiça ao juiz de direito, com base em inquérito policial ou em outras informações - por exemplo, a denúncia feita diretamente pela própria vítima;

b) interrogação do acusado, acompanhado de defensor (os quais podem não comparecer);

c) apresentação de defesa escrita;

d) audiência para oitiva da vítima e das testemunhas, quando o juiz faz sua própria inquirição às testemunhas e à vítima (no caso em estudo, a criança e/ou o adolescente) sobre o crime e, em seguida, faz perguntas levantadas pelo promotor de justiça e pelo defensor, com o objetivo de conhecer a verdade sobre os fatos. Trata-se do chamado sistema presidencial, isto é, cabe exclusivamente ao juiz (presidente da audiência) fazer todas as perguntas - inclusive as proferidas por acusação e defesa -, tendo ele o poder-dever de censurá-las se considerá-las inadequadas ou impertinentes.

Fávero (2008) aponta que as declarações das vítimas são importantes, servindo como uma das provas. Contudo, o magistrado pode decidir que o acusado não esteja presente na audiência, como forma de proteção à vítima. Nesse processo, as normas para ouvir os adultos são as mesmas utilizadas para ouvir crianças e adolescentes, o que tem sido frequentemente questionado. A autora aponta ainda que:

[...] quando é possível estabelecer acordo entre defesa e acusação, a audiência com a vítima (criança e/ou adolescente) pode deixar de ser realizada, sendo substituída por avaliação técnica, geralmente realizada por assistentes sociais, psicólogos e/ou psiquiatras, a qual vai instruir a ação processual - que pode dar-se tanto na Justiça da Infância e Juventude para as medidas de proteção à criança e ao 
Reflexões sobre a atuação dos assistentes sociais e psicólogos junto à metodologia...

adolescente -, como na Justiça Criminal, onde se desenvolverá o processo penal em relação ao suposto abusador. Neste tipo de avaliação, os profissionais realizam estudo social, psicológico e/ou psiquiátrico, individualmente ou interdisciplinarmente (dependendo da composição e/ou articulação da equipe técnica interna ao Judiciário, ou pertencente à rede de atendimento, neste caso, geralmente vinculada à área da saúde). Em seguida, apresentam o laudo que registra o trabalho e as conclusões a respeito da situação, destacando-se que tal trabalho pode incluir respostas a quesitos, se levantados pelas partes envolvidas. A critério de cada magistrado, pode ser definida a participação do(s) profissional(is) na audiência para esclarecimentos técnicos, com base no estudo realizado. Ainda que sejam conhecidas as dificuldades para se operacionalizar a articulação da rede de atendimento, esse trabalho deve incluir em seu norte a articulação com a rede familiar e social para o necessário atendimento e acompanhamento do conjunto de pessoas envolvidas no abuso. (FÁVERO, 2008, p. 10).

A importância da atuação interdisciplinar tem sido alvo de muitos debates. A promotora de justiça do Rio Grande do Sul Veleda Dobke tem defendido em seus escritos a interdisciplinaridade na abordagem da violência sexual contra crianças e adolescentes no judiciário, afirmando que os profissionais do Direito precisam ouvir as demais disciplinas (DOBKE, 2001).

Dobke (2001) aponta que quando os profissionais do Direito não se sentirem capacitados para ouvir crianças e adolescentes vítimas de abuso sexual, pode ser nomeado um "intérprete", com formação em Psicologia evolutiva e capacitação na problemática do abuso sexual, para que por intermédio dele seja ouvida a vítima, sugerindo-se nesses casos inclusive a utilização da Câmara de Gesell. Tal ação tem como respaldo uma legislação que permite a nomeação de intérprete para ouvir surdos-mudos ou estrangeiros que não entendam a língua nacional, posta no artigo 223 do Código de Processo Penal (BRASIL, 1941).

A mesma promotora também menciona que a inquirição pode ser substituída por uma avaliação técnica, desde que defesa e a acusação concordem com isso. Outra possibilidade levantada é a criação de varas especializadas para trâmite desses crimes, as quais devem contar com operadores jurídicos especializados (DOBKE, 2001).

Daltoé Cezar (2007, p.60), magistrado gaúcho a quem se atribui a ideia da metodologia do $\mathrm{DSD}$, relata que, ao assumir a magistratura em vara criminal, encontrava algumas dificuldades para a inquirição de crianças e adolescentes, uma vez que "as informações prestadas na fase policial não se confirmavam em juízo", o que criava "situações de constrangimento e desconforto para todos". E as ações muitas vezes eram julgadas como improcedentes devido à insuficiência de provas. Desse modo, o magistrado colocou a possibilidade da inquirição de crianças e adolescentes por intermédio de um "profissional habilitado", e utilizando a Câmara de Gesell.

Mas, devido às dificuldades físicas dos prédios do Poder Judiciário para instalar a Câmara, optou-se por um projeto-piloto (no Fórum Central de Porto Alegre/RS), com a instalação de uma sala para depoimentos de crianças e adolescentes vítimas de abuso sexual, interligada por vídeo e áudio à sala formal de audiências. Na sala formal, permaneciam os operadores jurídicos, o réu e servidores da justiça, com possibilidade de interagir durante o depoimento, inclusive com o controle da câmera pelo computador da sala de audiências, com efeito zoom para a ampliação da imagem (CEZAR, 2007).

Para Cezar (2007), o ambiente proposto é mais acolhedor, com intervenções de técnicos devidamente preparados para tal finalidade, evitando-se assim perguntas inapropriadas, impertinentes, agressivas e desconectadas do objeto do processo e principalmente da condição do depoente.

Assim, em 6 de maio de 2003, ocorreu a primeira audiência do projeto $\mathrm{DSD}$, na Vara da Infância e Juventude de Porto Alegre, tendo como técnica responsável pela inquirição a psicóloga Dra. Márcia Rublescki. A audiência contava também com as presenças da Dra. Veleda Dobke e da Dra. Sônia Biehler da Rosa. A partir de então, foi enviado um ofício à direção do Foro de Porto Alegre, disponibilizando a sala por todas as manhãs, para que outros magistrados de Porto Alegre e de outras comarcas pudessem utilizá-la (CEZAR, 2007). 
Ainda de acordo com Cezar (2007), o projeto assumiu caráter institucional em 2004, com a aquisição pelo Tribunal de Justiça do Rio Grande do Sul de equipamentos mais qualificados, permitindo que o som e a imagem tivessem boa qualidade. Ele afirma que de abril de 2003 a dezembro de 2005 foram realizadas 398 inquirições na $2^{a}$ Vara da Infância e Juventude de Porto Alegre.

Em tais circunstâncias, com o intuito de garantir a validação do relato das crianças e adolescentes, Cezar (2007) deu início ao projeto Depoimento Sem Dano. Para o autor, é necessário que o técnico entrevistador tenha um papel facilitador para com o depoimento da criança, que possua habilidades de escuta, demonstre paciência, empatia e disposição para o acolhimento, e que proporcione ao depoente um momento de segurança, deixando-o à vontade durante a audiência.

Ele relata que essa metodologia é composta pelas seguintes fases: acolhimento, depoimento ou inquirição e acolhimento final/ encaminhamentos. $\mathrm{O}$ acolhimento inicial tem uma duração de quinze a trinta minutos. Inicia-se com a intimação do responsável pela criança ou adolescente, que deve comparecer com trinta minutos de antecedência para a audiência. Essa medida busca evitar o encontro dos menores de idade com o réu, pois o modo convencional não possui nenhuma medida preventiva para tal momento. Tais encontros podem abalar psicologicamente a criança ou o adolescente, comprometendo o depoimento com eventuais abalos no estado emocional do depoente. Em seguida, o técnico informa a criança e seu responsável a respeito dos papéis de juiz, promotor de justiça, advogado, técnico e depoente durante a realização do depoimento, aproveitando o momento para também apresentar a sala de audiências.

A etapa do depoimento ou inquirição dura de vinte a trinta minutos de gravação ininterrupta. A audiência é instruída pela forma processual vigente, penal ou civil, onde é de exclusividade do juiz o ato de dar início ao processo e de ordená-lo, e o técnico será o facilitador do depoimento da criança ou do adolescente (CEZAR, 2007).

No encerramento da inquirição, o arquivo de som e imagem é encaminhado para a degravação - dentro de um prazo máximo de setenta e duas horas. Em seguida, juntamente com o termo de degravação, o arquivo é anexado aos autos do processo, contendo na contracapa um disco com som e imagens do depoimento. Por questão de segurança e acessibilidade, a cópia do disco é mantida junto aos arquivos da $2^{\mathrm{a}}$ Vara da Infância e da Juventude (CEZAR, 2007).

Para Cezar (2007), a finalização do DSD acontece com o acolhimento final e com encaminhamentos. Esse é um dos fatores que o diferenciam do sistema convencional no trato com situações de violência. A fase de acolhimento final tem duração média de trinta minutos, nos quais o técnico permanece com a criança ou o adolescente - e também com a família deste, ao final da audiência. Esse momento acontece com o sistema de gravação desligado, para que sejam feitas devoluções do depoimento e da coleta de assinaturas no termo de audiência. De acordo com as necessidades identificadas pelo técnico, são realizadas intervenções, bem como encaminhamentos para atendimento junto à rede de proteção.

De acordo com Wolff (2008), essas etapas não acontecem necessariamente nessa sequência lógica. Há situações em que o técnico, em razão das condições que envolvem a criança ou o adolescente e o processo, sugere ao juiz providências quanto ao adiamento, cancelamento ou mudança do depoimento.

Segundo Cezar (2007), o "Depoimento sem Dano" contempla outra forma de inquirição e atende três objetivos principais:

- redução do dano durante a produção de provas em processos judiciais, nos quais a criança/adolescente é vítima ou testemunha;

- a garantia dos direitos desse público; valorização da sua palavra e respeito a sua condição de pessoa em desenvolvimento;

- a melhoria na produção da prova.

Em âmbito mundial, os procedimentos são feitos de maneira específica, conforme as diferentes legislações. No Brasil, após sua implantação em Porto Alegre, o DSD passou a ser utilizado em diferentes comarcas: onze do Rio Grande do Sul, além de outras cidades como Goiânia/GO, Serra/ES, Cuiabá/MT e Porto Velho/ RO (WOLFF, 2008). 
Nesse sentido, a partir da experiência de Porto Alegre, foi proposto um projeto de lei (PL n.4.126/2004) que trata do assunto. Apesar de o projeto não instituir o assistente social e/ou o psicólogo como inquiridor, destacamos que essa experiência iniciou-se com a participação desses profissionais, o que se repetiu nas outras experiências colocadas em execução, levando tanto o Conselho Federal de Psicologia (CFP) quanto o Conselho Federal de Serviço Social (CFESS) a se posicionar contra tais atuações (FÁVERO, 2008; CFESS, s/d).

Nas justificativas para a existência de uma lei brasileira que normatize a inquirição de crianças ou adolescentes vítimas ou testemunhas de violência sexual, alude-se com frequência a algumas legislações, como o Código de Processo Penal Brasileiro (1941), a Convenção Internacional sobre os Direitos da Criança (1989) e o Estatuto da Criança e do Adolescente (1990).

No Código de Processo Penal Brasileiro de 1941, encontramos:

Art. 201. Sempre que possível, o ofendido será qualificado e perguntado sobre as circunstâncias da infração, quem seja ou presuma ser o seu autor, as provas que possa indicar, tomando-se por termo as suas declarações.

Art. 202. Toda pessoa poderá ser testemunha (BRASIL, 1941, grifo nosso).

Entretanto, estudiosos contrários à inquirição de crianças e adolescentes afirmam que o Código de Processo Penal versa sobre a possibilidade de o "ofendido" ser questionado e que toda pessoa "poderá" ser testemunha. Além disso, apontam que o Artigo 208 dispõe que a testemunha de menos de 14 anos não é obrigada a depor: "Não se deferirá o compromisso a que alude $\mathrm{o}$ art. 203 aos doentes e deficientes mentais e aos menores de 14 (quatorze) anos, nem às pessoas a que se refere o art. 206".

O Estatuto da Criança e do Adolescente também dispõe sobre tal questão. Ele estabelece, no Artigo $15^{\circ}$ do capítulo II, "Do Direito à Liberdade, ao Respeito e à Dignidade", que a criança e o adolescente têm direito à liberdade, ao respeito e à dignidade como pessoas humanas em processos de desenvolvimento e como sujeitos de direitos civis, humanos e sociais.
E o Artigo $16^{\circ}$ desta lei especifica "O direito a liberdade compreende os seguintes aspectos: (...) II - opinião e expressão" (BRASIL, 1990).

Porém, muitos estudiosos destacam que essa legislação não coloca a obrigatoriedade do depoimento. Segundo Azambuja (2010), existe diferença entre inquirir e ouvir a criança. Inquirir significa perguntar, indagar, fazer perguntas direcionadas, investigar, pesquisar. Ouvir, por sua vez, significa escutar o que a criança tem a dizer, dar ouvidos, dar atenção às suas palavras. Assim, a procuradora questiona: exigir da criança a responsabilidade pela produção da prova de violência sexual, por meio da inquirição, não seria uma nova violência contra a criança? Seria ela obrigada a depor?

Segundo Azambuja (2010), os legisladores passaram a valorizar a opinião da criança e do adolescente principalmente a partir do ECA e do Código Civil de 2002, e em especial nos feitos que envolvem a colocação em família substituta por meio da guarda, da tutela ou da adoção. Inclusive, a nova Lei da Adoção, em vigor desde 3 de novembro de 2009 , estende para a tutela e a guarda a obrigatoriedade do consentimento do adolescente na sua colocação em família substituta, o que só era exigido com relação à adoção.

Para Brito (2008), o ECA, ao prever a proteção integral da criança e do adolescente, traz consigo três princípios fundamentais: as crianças e os adolescentes são sujeitos de direitos; são pessoas em condição peculiar de desenvolvimento e são prioridade absoluta. Nessa óptica, a autora questiona: no processo de inquirição, esse público estaria participando na condição de sujeito de direitos e em condição peculiar de desenvolvimento ou estaria, no caso do Sistema Judiciário Brasileiro, se configurando como objeto para a produção de provas contra o agressor?

Por outro lado, Souza (2010) enfatiza a condição das políticas sociais em tempos neoliberais, que muitas vezes são incapazes de proteger e viabilizar direitos, mesmo que a proteção aos direitos esteja preconizada nas legislações do país. Para essa assistente social, não há dúvida de que o contexto atual, em uma conjuntura na qual os recursos para a garantia dos direitos têm sofrido restrições, faz crescer o número de pessoas favoráveis ao endurecimento da legislação. 
Assim, uma parcela da sociedade tem defendido saídas criminalizantes para suas próprias contradições e dificuldades. A mesma sociedade que exige tais alternativas estimula o consumo exacerbado, prioriza valores individualistas, a acumulação de bens, e estimula a sexualização precoce (SILVA, 2009).

Desse modo, aqueles que se colocam contrários a essa metodologia também afirmam que o Código de Processo Civil Brasileiro de 1973 não autoriza o depoimento dos menores de 16 anos. Desse modo, a inquirição de crianças estaria caminhando contra o que está exposto na legislação. Por outro lado, Cezar (2007, p. 71), que é favorável à metodologia, destaca:

O Código de Processo Civil de 1973, embora de origem mais recente que o Código de Processo Penal, proíbe que os menores de dezesseis anos prestem depoimento como testemunhas (artigo $405 \S 1^{\circ}$, inciso III), assim estando em oposição não só ao que dispõe a Convenção Internacional sobre os Direitos da Criança, como também a diversos dispositivos presentes no Estatuto da Criança e do Adolescente, que autorizam exatamente o contrário, como forma de valorizá-la como sujeito de direito que deve ser tratada não como incapaz, mas como pessoa em estágio de desenvolvimento ainda incompleto.

Outro marco legal brasileiro que torna possível a existência do DSD é o Artigo 156 do Código de Processo Penal, que passou a admitir a produção antecipada de provas por meio da Lei n.11.690, de 2008. Essa reforma permite que o depoimento seja gravado em vídeo no momento do ajuizamento das provas, para que possa ser anexado ao processo (SANTOS; GONÇALVES, 2008).

Como podemos observar, ainda não existe um consenso sobre essa prática no Brasil. Mas, dadas a importância dessa temática e a polêmica que a envolve, buscamos realizar um debate introdutório expondo a opinião de alguns profissionais sobre a atuação dos assistentes sociais e psicólogos na aplicação dessa metodologia.

\section{Percurso metodológico da pesquisa empírica}

Esta pesquisa é resultado de um trabalho de conclusão de curso na área de Serviço Social, intitulado "Depoimento sem Dano em análise: a opinião dos profissionais" e defendido em 2010 no Estado do Espírito Santo. Configura-se como um estudo de caso cuja abordagem é qualitativa. Segundo Gonçalves (2003), esse método preocupa-se em compreender e interpretar os fenômenos, ou seja, ele considera o sentido das palavras e ações proferidas por seus autores.

A coleta de dados foi realizada nos anos de 2009 e 2010. Recorremos a bibliografia e a documentos da área e, em seguida, procedemos ao questionamento de oito participantes, por meio de entrevistas semiestruturadas e questionários. De acordo com Lakatos e Marconi (2007), a entrevista caracteriza-se pelo encontro entre duas pessoas, com a intenção de obter dados referentes a um determinado assunto em uma conversa de caráter profissional, e o questionário é constituído por uma série de perguntas ordenadas, que são respondidas por escrito, sem a presença do entrevistador.

Para a seleção dos entrevistados, entramos em contato com os Conselhos Regionais de Serviço Social e Psicologia do Estado do Espírito Santo, solicitando que fossem indicados profissionais das áreas de Serviço Social, Psicologia e Direito que estudam o assunto e/ou participaram dos eventos nacionais de discussão do tema. A escolha dessas áreas de conhecimento se deve ao fato de serem áreas ligadas diretamente à metodologia do DSD, de acordo com o modelo pioneiro do Rio Grande do Sul. Além disso, a participação dos profissionais do Estado do Espírito Santo na pesquisa é relevante, uma vez que a metodologia do DSD se desenvolveu também no município de Serra/ES.

Dos oito participantes selecionados, sete exercem atividades (no Estado do Espírito Santo) ligadas à temática da violência sexual contra crianças e adolescentes e apenas um profissional participante não reside no referido Estado - contudo, ele foi inserido na pesquisa por sua importância nacional e até mesmo internacional na problematização do tema. Ou seja, todos os participantes da pesquisa atuam na área judiciária e/ou nos movimentos sociais.

Dos oito participantes selecionados, quatro responderam ao roteiro de entrevista em dia e horário agendados e quatro responderam às mesmas perguntas em forma de questionário, devido à distância ou à indisponibilidade de 
horários. Nesses casos, os questionários e Termos de Consentimento Livre e Esclarecido foram enviados por e-mail e devolvidos pelos Correios no endereço de um dos pesquisadores. Todos foram informados sobre os objetivos da pesquisa e assinaram o Termo de Consentimento Livre e Esclarecido.

Para manter o sigilo sobre o nome dos participantes, eles serão identificados pelas seguintes siglas: AD1 para advogado, AS1, AS2, AS3 e AS4 para assistentes sociais, J1 e J2 para juízes de direito e P1 para psicólogo. Os dados foram analisados a partir da Análise de Conteúdo (BARDIN, 1977).

\section{Resultados}

As respostas dos entrevistados, bem como as análises das mesmas, foram agrupadas em torno de quatro questões: opinião quanto à metodologia do DSD; posicionamento dos entrevistados quanto à realização da inquirição pelos assistentes sociais e psicólogos; opinião dos participantes quanto ao posicionamento dos Conselhos Federais de Serviço Social e Psicologia; e a possibilidade de a inquirição ser realizada por outros profissionais que não sejam assistentes sociais ou psicólogos, já que seus respectivos Conselhos vetaram a participação dessas categorias.

\section{Diferentes opiniões sobre a metodologia do DSD}

Ao serem questionados sobre a metodologia do DSD, os profissionais se posicionaram da seguinte forma: AS1 entende a metodologia como "forma de minimizar o dano sofrido pela vítima"; AS2 declara ser este um método inovador; AS3 acredita ser um método ineficaz para alcançar o objetivo a que se propõe; AS4 acredita que a metodologia necessita de mais estudos; AD1 acha que a proposta precisa ser aperfeiçoada; $\mathrm{J} 1$ acredita que o método atende aos reais interesses da criança; J2 relata que o método busca a verdade e a diminuição da impunidade do agressor; P1 declara que essa metodologia traz danos para a "vítima", tanto é que se propõe a terminologia de "Depoimento Especial".

Dessa forma, podemos afirmar que, dos oito entrevistados, seis acham a proposta interessante (AS1, AS2, AS4, AD1. J1, J2), mesmo que carecendo (na opinião de alguns) de algumas modificações.

Tendo em vista a urgência no que tange à proteção dos direitos da criança e do adolescente, frequentemente encontramos afirmações favoráveis a essa proposta, pois muitos acreditam que essa metodologia, se bem explorada, poderia solucionar a questão. Nessa perspectiva, o Quadro 4 elenca os pontos positivos e os pontos negativos apresentados na literatura sobre o assunto. 
Quadro 4 - Pontos positivos e negativos atribuídos ao DSD

\begin{tabular}{|c|c|}
\hline Pontos positivos atribuídos ao DSD & Posicionamentos contrários à metodologia \\
\hline $\begin{array}{l}\text { Facilita a obtenção de provas e a punição do } \\
\text { agressor. }\end{array}$ & $\begin{array}{l}\text { Tem como principal finalidade a punição do agressor, e } \\
\text { não a garantia de proteção integral à vítima. }\end{array}$ \\
\hline $\begin{array}{c}\text { Reduz os danos durante a produção de } \\
\text { provas em processos judiciais que envolvem } \\
\text { crianças e adolescentes. }\end{array}$ & $\begin{array}{l}\text { Oferece danos aos envolvidos, tanto é que profissionais } \\
\text { sugerem a mudança da terminologia para "depoimento } \\
\text { especial", ou "inquirição especial". }\end{array}$ \\
\hline $\begin{array}{l}\text { É importante, uma vez que os profissionais } \\
\text { ouvem a criança e valorizam sua fala. } \\
\text { Inclusive o próprio ECA, em seu Artigo 16, } \\
\text { afirma que a criança e o adolescente têm } \\
\text { direito a opinião e expressão. }\end{array}$ & $\begin{array}{l}\text { O ECA estabelece o direito (e não a obrigação) à } \\
\text { expressão. Assim, o direito de ser ouvido não tem o } \\
\text { mesmo significado de "ser inquirido". }\end{array}$ \\
\hline $\begin{array}{l}\text { É um caminho eficaz para a busca da } \\
\text { "verdade". }\end{array}$ & $\begin{array}{c}\text { O que é verdade para uma criança e um adolescente } \\
\text { nos casos que envolvem violência? E quais são as } \\
\text { consequências em dizer ou não a verdade? A criança e o } \\
\text { adolescente estarão cientes disso? }\end{array}$ \\
\hline $\begin{array}{l}\text { A criança e o adolescente serão ouvidos } \\
\text { e inquiridos por profissionais capacitados, } \\
\text { como assistentes sociais e psicólogos. }\end{array}$ & $\begin{array}{l}\text { A inserção de assistentes sociais e psicólogos nesse tipo } \\
\text { de intervenção poderia naturalizar o despreparo de outros } \\
\text { profissionais. }\end{array}$ \\
\hline $\begin{array}{l}\text { Essa forma de atuação reconhece a } \\
\text { importância da interdisciplinaridade. }\end{array}$ & $\begin{array}{c}\text { Alguns estudiosos da área apontam que essa prática fere } \\
\text { a autonomia e contribui para a subalternidade profissional } \\
\text { de alguns profissionais em relação ao juiz. }\end{array}$ \\
\hline $\begin{array}{l}\text { O ambiente proposto para a inquirição é um } \\
\text { local acolhedor, onde o depoente não teria } \\
\text { contato físico e/ou visual com o suposto } \\
\text { agressor. Seria um lugar onde as crianças e } \\
\text { adolescentes ficariam à vontade para depor. }\end{array}$ & $\begin{array}{l}\text { A questão discutida não é se o ambiente é adequado ou } \\
\text { não, mas qual é a finalidade da proposta. Além disso, o } \\
\text { ambiente proporciona a ocultação do agressor e demais } \\
\text { integrantes da sala, e isso seria o mesmo que mentir para } \\
\text { os depoentes. Outras questões a serem consideradas } \\
\text { são: os depoentes estariam cientes de quem realmente } \\
\text { os observa? Esse tipo de atitude seria válido para } \\
\text { obtenção de provas judiciais? A criança e o adolescente } \\
\text { estariam conscientes das consequências de sua fala? }\end{array}$ \\
\hline $\begin{array}{l}\text { É um "novo fazer profissional", tanto para } \\
\text { assistentes sociais como para psicólogos, } \\
\text { uma vez que essa prática poderia ser } \\
\text { exercida por ambos os profissionais. }\end{array}$ & $\begin{array}{l}\text { Segundo os Conselhos Federais de Psicologia e de } \\
\text { Serviço Social, essa prática fere os compromissos e o } \\
\text { agir profissional das duas profissões. }\end{array}$ \\
\hline
\end{tabular}

Fonte: Brito 2008; Azambuja, 2008; Cezar, 2007; Wolff, 2008; Fávero, 2008.

\section{A inquirição fere alguma legislação das profissões de Serviço Social e Psicologia?}

O Projeto de Lei que dispõe sobre a inquirição de crianças e adolescentes em processos judiciais não determina a participação do assistente social e/ou do psicólogo como inquiridor desse público. Contudo, tal prática, que teve início em Porto Alegre/RS, sempre contou com tais profissionais. Esse é um modelo difundido para o restante do país, mas atualmente vem sendo problematizada a participação dos referidos profissionais nesse tipo de trabalho.

De acordo com Cezar (2007), o papel do Serviço Social e da Psicologia no DSD é auxiliar o juiz, facilitando a comunicação deste com as crianças e os adolescentes inquiridos, pois é muito importante que o técnico entrevistador tenha, entre outras aptidões, habilidade para ouvir, empatia e paciência.

Ao serem questionados sobre a participação do assistente social e/ou do psicólogo nesse processo, quatro entrevistados (AS1; AS2; J1; J2) se posicionaram a favor de tal participação; dois (AS4; AS3) colocaram-se contra e dois (AD1; P1) demonstraram dúvidas, esclarecendo a necessidade de um debate mais profundo sobre a situação. 
Reflexões sobre a atuação dos assistentes sociais e psicólogos junto à metodologia...

Dentre as falas dos que se posicionaram a favor, podemos destacar duas:

[...] na perspectiva original do projeto é que esses profissionais, tanto de Psicologia quanto de Serviço Social, fizessem a inquirição, fosse um instrumento de inquirição dessas crianças judicialmente (AD1).

[...] as assistentes sociais e os psicólogos atuam basicamente como técnicos facilitadores do depoimento [...] Os técnicos utilizam o referencial teórico da entrevista cognitiva, que permite um relato livre da criança, sem perguntas diretas, para que não ocorra uma indução [...] (J1).

Contudo, vozes discordantes (AS3, AS4) afirmam que o papel do assistente social e/ ou do psicólogo na metodologia se limita ao de "porta voz" de alguém que possui poder de decisão em relação às perguntas voltadas aos envolvidos (nesse caso, o juiz).

Perguntamos aos participantes da pesquisa se a realização da inquirição por meio dessa metodologia fere alguma regulamentação das profissões de Serviço Social e Psicologia. Dos oito profissionais entrevistados, quatro (AS1, AS2, J1, J2) disseram que o DSD não fere nenhuma regulamentação dessas profissões. Vejamos alguns relatos:

[...] proibir que um técnico, um profissional de Serviço Social ou de Psicologia, [...] participe disso aí, para mim é um retrocesso [...] O projeto não é perfeito [...] nós que estamos aplicando há pouco tempo, nós estamos vivendo algumas coisas, cada audiência que a gente realiza, a gente vai avaliando [...] vai buscando onde é que tá errado, onde é que não tá, e vai buscando acertar, mas sempre olhando para essa criança que está na nossa frente, sempre pensando nela, sempre pensando no quanto é importante pra ela que essa pessoa seja responsabilizada pelo que fez. Porque um crime maior do que foi cometido com ela, é ela saber que esse agressor está solto por aí, e que não tem provas contra ele [...] (AS1).

[...] nos sentimos muito tristes, desrespeitadas e cerceadas [...] Vou falar de mim [...] tudo bem que eu me sinta cerceada, é [...] no meu direito de profissional, de usar essa ou aquela técnica, de trabalhar dentro daquela outra metodologia com a resolução do Conselho Federal. Eu achei que foi extremamente, muito ditatorial [...] assim impositivo (AS2).

[...] Nenhuma profissão possui apenas um tipo de prática. Não há infringência a nenhuma norma de conduta ética (J1).

Para dois participantes (AS3 e AS4), essa prática fere a autonomia dos profissionais, e outros dois (AD1 e P1) não se posicionaram. Segundo AS3:

[...] fere o projeto profissional que é composto pelos fundamentos teórico-metodológicos, ético-políticos e técnico-operativos, ou seja, o profissional de Serviço Social goza de autonomia técnica no exercício de suas funções e no DSD não é solicitado ao assistente social uma intervenção profissional, e sim uma atribuição lhe é imposta [...].

Nessa óptica, tanto o Conselho Federal de Psicologia quanto o Conselho Federal de Serviço Social já se posicionaram contra a realização dessa atividade por esses profissionais. Segundo o Conselho de Psicologia, essa metodologia distancia-se do trabalho a ser realizado pelo psicólogo.

Para Brito (2008), esse tipo de trabalho apresenta uma confusão de papéis ou uma indiferenciação de atribuições entre os profissionais, e não tem como objetivo a avaliação psicológica. Está sempre em jogo a "busca pela verdade", e esta não é atribuição ou competência do psicólogo, ao menos a verdade tal qual ela é conhecida no âmbito judicial. Além disso, a autora aponta que nesse tipo de metodologia não há tempo para entrevistas com os responsáveis, com o chamado "agressor", e nem para estudos psicológicos acerca do caso, o que reduz em muito a situação.

A busca pela verdade parece ser uma das questões centrais na discussão da Psicologia. Brito (2008) aponta que a avaliação de suspeita de violência sexual é uma atividade minuciosa e carece de uma metodologia rigorosa, pois a avaliação poderá ocorrer justamente quando a família se encontra em momento de crise devido à natureza da denúncia. Além disso, não se pode esquecer de que, quando o abuso é praticado pelo pai, frequentemente a criança abusada o ama e o detesta ao mesmo tempo, motivo pelo 
qual $85 \%$ das vítimas meninas querem ver cessar o abuso sexual, mas não desejam necessariamente que seu pai seja preso.

Por sua vez, Azambuja (2008) questiona se a criança, ao ser inquirida, compreenderia as consequências de suas declarações, pois elas possuem dificuldades para entender ou diferenciar situações carinhosas das ocorrências caracterizadas como abuso, até porque o abuso pode acontecer sem violência física.

Alguns pesquisadores destacam que a criança por vezes não possui clareza sobre o fato que vivenciou, repetindo histórias que lhe foram contadas por pessoas de sua confiança, com quem mantém laços de afeto, reproduzindo fielmente afirmações que lhe foram transmitidas. Em muitos casos, pode ocorrer a alienação parental, ${ }^{9}$ quando uma criança é estimulada pelo pai ou pela mãe a interromper os laços afetivos com o outro cônjuge, gerando uma situação de não aceitação em relação ao outro genitor (SOUZA, 2010; GOMES, 2011).

No caso do Serviço Social, Wolff (2008) reconhece que a metodologia do DSD não seria uma atribuição privativa do assistente social. Acredita que poderia ser uma competência profissional tanto de assistentes sociais quanto de psicólogos. Para a autora, essa prática, ao ser realizada pelo assistente social, pode ser sustentada pelo Código de Ética, pela Lei de Regulamentação da Profissão e pelas Diretrizes Curriculares propostas para a formação de Assistentes Sociais. No Quadro 5, podemos observar os elementos que, segundo a autora, respaldam a realização dessa metodologia.

\footnotetext{
${ }^{9}$ Hoje, no Brasil, existe a Lei da alienação parental (Lei n.12.318), que foi sancionada no dia 26 de agosto de 2010. Esta lei prevê medidas que vão desde o acompanhamento psicológico até a aplicação de multa, ou mesmo a perda da guarda da criança para pais que estiverem alienando os filhos. Para maiores informações sobre o assunto, consultar a referência indicada no texto.
} 
Quadro 5 - Elementos que respaldam a atuação do assistente social, segundo Wolff (2008)

\begin{tabular}{|c|c|c|}
\hline Código de Ética do Serviço Social & $\begin{array}{l}\text { Lei de Regulamentação da } \\
\text { Profissão }\end{array}$ & Diretrizes Curriculares \\
\hline $\begin{array}{l}\text { A autora destaca que o reconhecimen- } \\
\text { to da liberdade, a defesa intransigente } \\
\text { dos direitos humanos; a ampliação e } \\
\text { consolidação da cidadania e o compro- } \\
\text { misso com a qualidade dos serviços } \\
\text { prestados à população são princípios } \\
\text { que dão sustentação à atuação do } \\
\text { Assistente Social na Metodologia do } \\
\text { DSD. } \\
\text { O Código de Ética disciplinaria também } \\
\text { questões relacionadas ao trabalho do } \\
\text { Serviço Social no DSD, como o Artigo } \\
2^{\circ} \text {, alínea 'h', que versa sobre autono- } \\
\text { mia profissional, bem como o Artigo } 5^{\circ} \text {, } \\
\text { alíneas 'b', 'f', 'h' e 'g'. } \\
\text { Para a autora, por meio dessa prática } \\
\text { seria possível implementar os deveres } \\
\text { previstos no Artigo } 10^{\circ} \text {, que se referem } \\
\text { à relação com outros profissionais, es- } \\
\text { pecialmente nas alíneas 'd', e 'e'. } \\
\text { Quanto ao sigilo profissional previsto } \\
\text { nos Artigos } 15^{\circ} \text { a } 18^{\circ}, \text { foram constata- } \\
\text { das duas situações. Uma refere-se ao } \\
\text { depoimento propriamente dito, que é } \\
\text { gravado e passa a fazer parte do pro- } \\
\text { cesso criminal, destacando que o pro- } \\
\text { cesso com o depoimento de crianças } \\
\text { e adolescentes corre em segredo de } \\
\text { justiça, ficando o depoimento acessível } \\
\text { às partes. Outra situação são os pro- } \\
\text { cedimentos da etapa de acolhimento } \\
\text { e retorno, que diz respeito somente ao } \\
\text { profissional, à criança, ao adolescente } \\
\text { e ao familiar. }\end{array}$ & $\begin{array}{l}\text { Quanto à Lei de Regulamen- } \\
\text { tação Profissional, a autora } \\
\text { sugere que o trabalho realizado } \\
\text { responde ao Artigo } 4^{\circ} \text { : Inciso } \\
\text { III - Encaminhar providências, } \\
\text { prestar orientação social a in- } \\
\text { divíduos, grupos e populações; } \\
\text { Inciso V: Orientar indivíduos e } \\
\text { grupos de diferentes segmen- } \\
\text { tos sociais no sentido de iden- } \\
\text { tificar recursos e fazer uso dos } \\
\text { mesmos no atendimento e na } \\
\text { defesa de seus direitos; e os in- } \\
\text { cisos VII e VIII, que se referem } \\
\text { à elaboração de pesquisas so- } \\
\text { bre a realidade social e à as- } \\
\text { sessoria no âmbito dos temas } \\
\text { pertinentes às atividades reali- } \\
\text { zadas pelo Serviço Social. }\end{array}$ & $\begin{array}{l}\text { Wolff (2008) aponta que as } \\
\text { diretrizes curriculares es- } \\
\text { tabelecem que a formação } \\
\text { profissional deve possibilitar } \\
\text { a capacitação teórico-me- } \\
\text { todológica e ético-política } \\
\text { como requisito fundamental } \\
\text { para o exercício de ativi- } \\
\text { dades técnico-operativas. } \\
\text { Isso deve ser cumprido com } \\
\text { vistas, entre outros aspec- } \\
\text { tos, a desvelar as possibili- } \\
\text { dades de ação contidas na } \\
\text { realidade e a identificação } \\
\text { das demandas presentes } \\
\text { na sociedade, visando a } \\
\text { formular respostas para o } \\
\text { enfrentamento da questão } \\
\text { social. As competências e } \\
\text { habilidades previstas pelas } \\
\text { Diretrizes Curriculares tam- } \\
\text { bém definem um profission- } \\
\text { al que tenha capacidade } \\
\text { para orientar a população } \\
\text { na identificação de recursos } \\
\text { para atendimento e defesa } \\
\text { de seus direitos, bem como } \\
\text { para realizar visitas, perí- } \\
\text { cias técnicas, laudos, infor- } \\
\text { mações e pareceres sobre } \\
\text { a matéria de Serviço Social. }\end{array}$ \\
\hline
\end{tabular}

Fonte: Wolff, 2008.

Contudo, um documento elaborado pelo CFESS (s/d) se posiciona contrariamente ao exercício profissional dos assistentes sociais no apoio a essa metodologia. O material chama a atenção para a necessidade de que os assistentes sociais se reconhecerem não somente como agentes técnicos, mas também como agentes ético-políticos. E ressalta que é preciso pensar sobre qual é a finalidade dessa metodologia e qual seria a prioridade na atuação dos assistentes sociais.

Para o CFESS (s/d), se, no âmbito geral, percebemos a volta do conservadorismo no que tange às discussões dos fenômenos sociais e a retração do Estado na efetivação dos direitos humanos, no âmbito particular, com relação à profissão, visualizamos a tentativa de subalternização, de culpabilização das famílias, de retorno às práticas conservadoras em novas roupagens. Assim, parte-se do princípio de que essa metodologia seria uma ação que retira e/ou dificulta a possibilidade de o profissional elaborar as estratégias de sua intervenção, de acordo com a finalidade e os propósitos teóricos e éticopolíticos do Serviço Social, além de escamotear as raízes do problema. 


\section{Opinião dos entrevistados quanto à posição do CFESS e do CFP}

Com a divulgação dessa nova prática, iniciou-se uma movimentação das entidades representativas dos profissionais envolvidos e dos órgãos vinculados ao planejamento e à execução de políticas voltadas à garantia dos direitos da criança e do adolescente. Posicionaram-se favoravelmente à prática: a Associação Brasileira de Magistrados e Promotores da Infância (ABMP); o Conselho Nacional de Direitos da Criança e do Adolescente (Conanda); a Secretaria Especial de Direitos Humanos da Presidência da República (SEDH); a Sociedade de Psiquiatria do Rio Grande do Sul e o Conselho Regional de Serviço Social 10a Região (WOLFF, 2008).

Por sua vez, os Conselhos Federais de Serviço Social e de Psicologia se posicionam contra a participação dos respectivos profissionais como inquiridores do método DSD. Dentre os envolvidos neste estudo, todos afirmaram ter ciência do posicionamento contrário dos ConseIhos Federais de Serviço Social e de Psicologia sobre a participação dos profissionais na aplicação do DSD, porém nem todos estão de acordo com tal posição.

Dos oito entrevistados, podemos afirmar que dois (AS3, AS4) concordam com a posição dos conselhos; quatro (AS1, AS2, J1, J2) não concordam com a posição dos conselhos e dois (AD1, P1) não se posicionaram, o que ressalta a necessidade de problematizações sobre o tema. Isso pode ser visualizado nas falas descritas a seguir:

[...] é uma loucura proibir um assistente social de realizar um trabalho que é de extrema importância, que é [...] visando simplesmente proteger a criança, se isso significa ter que [...] punir alguém é para isso que a justiça serve também, ela tá aqui para proteger a criança, mas ela tá aqui também para trazer elementos dentro de um processo [...] punir quem tem que ser punido, responsabilizar quem tem que ser [...] responsabilizado [...] (AS1).

[...] Eu não consigo entender em que fere o Código de Ética [...] aí eu me pergunto, vamos deixar da forma tradicional? Vamos continuar colocando a criança em frente ao agressor na sala de audiência? (AS2).
[...] a oposição dos Conselhos traz à tona a forma como tem sido feita a inquirição de crianças e adolescentes pelo [...] Poder Judiciário [...] Então, eu acho que o grande mérito do projeto foi tentar fazer uma alternativa a essa violação. Isso nós não podemos tirar [...] a minha avaliação do projeto é que ele tem esse mérito, o mérito de tentar trazer uma nova forma de inquirição que tenta garantir mais direitos para as crianças e adolescentes. Pode errar na metodologia, talvez [...] na forma de fazer, mas tem o mérito da intenção [...] Eu acho que talvez peque o projeto em segmentar, em fazer o papel do assistente social, do psicólogo e separe esse papel do juiz [...] acho que é muito difícil a gente pegar a experiência do Rio Grande do Sul e achar que num passe de mágica, que numa aprovação de uma lei no Congresso Nacional essa realidade vai ser imediatamente estendida pelo Brasil inteiro [...] o projeto tem muitos méritos, traz a discussão que nós precisamos fazer [...] precisamos efetivamente nos aprofundar em questões que apresentam para a autonomia profissional desses profissionais do poder judiciário (AD1).

[...] porque tamanha resistência desses conselhos, até porque eles não conhecem o projeto [...] Também nada propõem sobre alternativas para escutar crianças no sistema de justiça, permitindo que se presuma que pretendem que elas continuem a ser ouvidas no modelo tradicional. O CFESS, inclusive, editou uma resolução proibindo os assistentes sociais de trabalharem nos depoimentos, ameaçando puni-los (J1).

[...] eu não vejo nada demais na participação delas, porque estão só exercendo função, o trabalho delas, como prevê o estatuto, como prevê a lei (J2).

Segundo Brito (2008), em 2007 o Conselho Federal de Psicologia encaminhou ao Senado Federal uma moção contrária à aprovação do Projeto de lei 035/2007. No caso do Serviço Social, a discussão sobre a metodologia apareceu no conjunto CFESS/CRESS, mais precisamente no $36^{\circ}$ Encontro Nacional, realizado em Natal/ RN. A partir de então, o CFESS solicitou dois pareceres técnicos sobre tal metodologia. O primeiro foi elaborado pela Professora Dra. Eunice Fávero (2008). O segundo, pela assistente social Maria Palma Wolff (2008). 
Também ocorreu em Brasília, nos dias 12 e 13 de junho de 2008, um seminário intitulado "Precarização da formação acadêmica e implicações no exercício profissional", onde tal questão foi discutida. A partir de então, debates continuaram sendo realizados. No $38^{\circ}$ Encontro Nacional CFESS/CRESS, realizado nos dias 6 a 9 de setembro de 2009 em Campo Grande/MS, a Resolução do CFESS n.554/2009 foi discutida e aprovada. Essa resolução dispõe sobre o não reconhecimento da inquirição das vítimas crianças e adolescentes no processo judicial, sob a metodologia do Depoimento sem Dano (DSD), como atribuição ou competência do profissional de Serviço Social (CFESS, s/d).

\section{O processo de inquirição poderia ser realizado por outros profissionais?}

Os entrevistados foram questionados se a inquirição poderia ser realizada por outros profissionais que não fossem assistentes sociais e/ou psicólogos. Dentre os oito participantes, cinco (AD1, AS2, J2, AS3, AS1, AS4) afirmaram que sim, um (J1) disse que não e um (P1) não respondeu. Algumas opiniões podem ser verificadas a seguir:

[...] é o juiz que tomou os depoimentos, que olhou nos olhos das partes, que viu as reações das partes [...] porque não é só o que está no papel, a linguagem de uma testemunha, ou da própria vítima ou do agressor [...] não é só o que ele fala, mas é como ele fala, como ele se expressa, é a linguagem corporal [...] tudo isso diz muito para o seu convencimento, para saber o que aquela pessoa tá sentindo [...] portanto eu quero que o juiz, ao julgar uma ação que envolva a criança el ou adolescente, ele possa olhar no olho da criança e possa perceber na criança ou no sujeito que tem voz e que pode falar para ele, desde que ele não se coloque na posição de vitimizador novamente dessa criança (AD1).

Poderia desde que fosse um profissional habilitado [...] (AS2).

[...] a finalidade do projeto é que a criança seja ouvida não pelo juiz, e sim por uma pessoa apta [...] (J2).

Como pode ser constatado nessas falas, $A D 1$ entende que o próprio juiz poderia realizar a inquirição, levando em consideração que sua posição deveria ser de horizontalidade com a vítima. Para AS2, a criança e o adolescente poderiam ser ouvidos por outros profissionais, desde que estes fossem habilitados. E J2 afirma que crianças e adolescentes poderiam ser inquiridos por outro profissional desde que não fosse o juiz, pois este não é apto para esse tipo de intervenção.

Podemos notar que, no caso do Serviço Social, todos os profissionais entrevistados concordam com a metodologia, caso ela seja aplicada por outros profissionais. É importante considerar que a discussão sobre "qual profissional está apto para esse tipo de trabalho" não deve ser o único foco de nossa preocupação. Além das questões que envolvem o trabalho interdisciplinar, devemos também pensar se a criança e o adolescente em situação de violência sexual devem ser inquiridas (AZAMBUJA, 2008; FÁVERO, 2008).

Assim, ressalta-se que a discussão não engloba apenas a capacidade ou não daquele profissional para realizar tal tarefa. Se for assim, novamente estaremos colocando os direitos da criança e do adolescente em condição secundária, como se eles não fossem centrais nesse debate (AZAMBUJA, 2008; FÁVERO, 2008).

\section{Considerações finais}

Entendemos que o enfrentamento da violência, e, em especial, da violência sexual contra crianças e adolescentes, é urgente em nosso país. Do mesmo modo, afirmamos que não podemos ser coniventes com ações reducionistas e/ou omissas perante tal realidade.

Muitos estudos têm demonstrado a dificuldade dos profissionais em trabalhar com casos de violência sexual. Assim, por muitas vezes os casos são negados, evitados, escondidos. Alguns profissionais, por medo de se "envolver", preferem não tocar no assunto, para não ter "problemas" a serem resolvidos (AZAMBUJA, 2009). Nesse caso, consideramos positivo o retorno ao debate dessa problemática e a vontade que os profissionais têm demonstrado para a resolução da questão.

A partir das entrevistas feitas, visualizamos as tensões entre o que os Conselhos Federais de Serviço Social e Psicologia determinam e o cotidiano desafiador dos profissionais que atuam 
no Sistema de Garantia de Direitos, especialmente no setor judiciário. Verificamos, por exemplo, que, das quatro assistentes sociais entrevistadas, todas são favoráveis à metodologia, caso ela seja realizada por outro profissional. Ou seja, existe um desejo dos profissionais de encontrar uma forma concreta de proteger a criança e o adolescente e, ao mesmo tempo, de responsabilizar o agressor.

Assim, muitas são as estratégias adotadas com o intuito de contribuir para o enfrentamento desse problema. Mas, em que pese a boa vontade daqueles que lançam propostas nesse sentido, não podemos deixar de refletir sobre as ações propostas à luz da teoria e da crítica do pensamento social.

Nesse sentido, a metodologia do Depoimento sem Dano revela-se bastante polêmica. Ela traz implicações para a vida de todos, e inclusive para as relações entre Estado e sociedade. No que tange às crianças e adolescentes vítimas, devemos destacar a necessidade de sua proteção integral prevista no ECA.

Além disso, já tecemos diversas considerações sobre o dano que poderá ser causado às crianças e aos adolescentes; as consequências que a famigerada busca pela verdade pode ocasionar; o desrespeito ao direito de não se expressar; o sentimento que poderá ser gerado quando a vítima souber que falou para um público e que ofereceu provas contra pessoas que muitas vezes são de sua família, dentre outras questões.

No que tange ao agressor, demonstramos nossa preocupação com a atuação de profissionais que deveriam ter como fundamento a viabilização de direitos, como é o caso do Serviço Social. Mesmo sabendo que essa prática já não é mais permitida, cabe questionar como seria a participação de assistentes sociais na produção de provas contra alguém. Como esse profissional seria responsável pelo auxílio na produção de provas e, em seguida, seria responsável pelo atendimento ao agressor? Essa pergunta é pertinente na medida em que entendemos que é necessária a responsabilização de quem cometeu um crime, mas é necessário também o atendimento a esse agressor.

As famílias (da vítima e/ou do agressor) também motivam nossa inquietação. Sabemos que a violência perpassa todas as classes so- ciais; entretanto, tal situação é mais facilmente notificada no caso das classes menos favorecidas, seja porque estas procuram mais frequentemente os serviços públicos, seja pela própria intervenção profissional constantemente feita nesses lares. Então quem poderá assegurar que essa metodologia não será utilizada predominantemente nas famílias cujas vítimas são pobres? (FÁVERO, 2008). Poderia ocorrer uma reedição do Código do Menor, que tratava as crianças das classes ricas diferentemente das empobrecidas?

Elucidaremos também as implicações dessa metodologia para os profissionais. No caso dos operadores do Direito, tal metodologia pode fazê-los acreditar que o sistema de justiça só precisa de mais um procedimento para seu brilhante funcionamento. Mas sabemos que não é assim. O sistema de justiça brasileiro precisa ser debatido com muita seriedade e precisamos traçar novos rumos, ou seja, deve acontecer uma mudança em todo o sistema.

A aplicação desta ou daquela metodologia não melhorará muito o que já está posto. Os referidos profissionais também não devem naturalizar o fato de que "não possuem capacitação para falar com crianças e adolescentes". Com quem, então, esses profissionais podem dialogar? Podem dialogar com idosos? E com pessoas com deficiência? Devemos ter cuidado, ou, daqui a alguns anos, muitos alegarão que não são aptos a falar com este ou aquele cidadão.

Os profissionais devem estar a serviço da sociedade e precisam falar com quem quer que seja, pois todos são cidadãos de direito, ou deveriam ser. Essa posição de superioridade, verticalizada e autoritária, não engrandece em nada nossa nação, e tende a alargar as diferenças sociais, além de ser também uma forma de opressão.

Para os profissionais que não são da área do Direito, essa metodologia certamente tende à subalternização de algumas profissões. Como mencionado, os profissionais se colocariam como "intérpretes", como uma espécie de "extensão do juiz". Segundo Fávero (2008), a justificativa da interdisciplinaridade parece não caber ao DSD, uma vez que, se o técnico for assistente social, não é solicitada a ele uma intervenção profissional e sim uma atuação como "intérprete", ou como "porta voz" de alguém que 
tem o poder de decisão em relação às perguntas e ao destino da criança e/ou familiares.

Por fim, destacamos as mudanças na relação entre sociedade e Estado. O Estado há muito deixou de ser protetor, principalmente no caso brasileiro, onde não existiu o Welfare State (BEHRING; BOSCHETTI, 2006). Segundo Fávero (2008), hoje vivemos a ampliação do Estado penal (controlador, punitivo) em detrimento do Estado social.

Diante disso, pensamos: quais são as políticas sociais efetivas (e que realmente se concretizam) para a prevenção e a garantia de direitos? Será que em tempos neoliberais a metodologia do Depoimento sem Dano conseguiria realmente efetivar os direitos de nossas crianças e adolescentes? Ou devem ser realizadas mudanças mais profundas e radicais? Essas são apenas algumas questões para futuras discussões a serem realizadas sobre a metodologia apresentada.

\section{Referências}

ABESS/CEDEPSS. Diretrizes gerais para o Curso de Serviço Social. In: Caderno ABESS n.7. São Paulo: Cortez, 1996.

AZAMBUJA, M. R. F. A inquirição da criança e do adolescente no âmbito do judiciário. In: CONSELHO FEDERAL DE PSICOLOGIA. A escuta de crianças e adolescentes envolvidos em situação de violência e a rede de proteção. Brasília: CFP, 2010. p.13- 29.

A inquirição da vítima de violência sexual intrafamiliar à luz do melhor interesse da criança. In: Conselho Federal de Psicologia. Falando sério sobre a escuta de crianças e adolescentes envolvidos em situação de violência e a rede de proteção: propostas do Conselho Federal de Psicologia. Brasília: Conselho Federal de Psicologia, 2009. p. 27-70.

Violência sexual intrafamiliar: é possível proteger a criança? Revista Virtual Textos e Contextos, Porto Alegre, n.5, nov. 2006.

BARDIN, L. Análise de conteúdo. Lisboa: Ed. 70, 1977.

BEHRING; E. R.; BOSCHETTI, I. Política Social: fundamentos e história. São Paulo: Cortez, 2006.

BRASIL. Constituição (1988). Constituição [da] República Federativa do Brasil. Brasília: Senado Federal, 1988.
Decreto lei n.3.689, de 3 de outubro de 1941. Diário Oficial [da] República Federativa do Brasil, Brasília, 1941.

Lei 8.069/1990. Estatuto da Criança e do Adolescente. Rio de Janeiro, 1990.

Lei n.8.662, de 07 de junho de 1993. Dispõe sobre a profissão de Assistente Social e dá outras providências. Diário Oficial [da] República Federativa do Brasil, Brasília, 1993.

BRITO; L. M. T. Diga-me agora... O depoimento sem dano em análise. Revista Psicologia Clínica, Rio de Janeiro, v. 20, n.2, p.113-25, 2008.

CARVALHO, D. B. B. Criança e adolescente. In: Caderno de Capacitação em Serviço Social e Política Social. Módulo 03. Brasília: UNB, Centro de EDUCAÇÃO Aberta, 2000.

CEZAR, J. A. D. Depoimento sem Dano: uma alternativa para inquirir crianças e adolescente em processos judiciais. Porto Alegre: Ed. Livraria do Advogado, 2007.

CONSELHO FEDERAL DE SERVIÇO SOCIAL. Código de Ética dos Assistentes Sociais de 13 de março de 1993.

CONSELHO FEDERAL DE SERVIÇO SOCIAL. Resolução CFESS n.554/2009, de 15 de setembro de 2009. Disponível em: <http://www.cfess.org.br/ arquivos/Resolucao_CFESS_554.pdf >Acesso em: 17 set. 2013.

DESLANDES, S. F. Prevenir a violência: um desafio para profissionais de saúde. 2.ed. Rio de Janeiro: Fiocruz/ENSP/Claves-Jorge Careli, 1994.

DOBKE, V. Abuso sexual: a inquirição de crianças uma abordagem interdisciplinar. Porto Alegre: Ricardo Lenz, 2001.

FALEIROS, E. O abuso sexual contra crianças e adolescentes: os (des)caminhos da denúncia. Brasília, DF: Secretaria Especial dos Direitos Humanos, 2003.

FÁVERO, E. T. Parecer contrário: Metodologia Depoimento sem Dano. São Paulo: CFESS, 2008.

GOMES, J. L. P. Síndrome da alienação parental: o bullying familiar. São Paulo: Editora Imperium, 2011.

GONÇALVES, H. A. Manual de projeto de pesquisa científica. São Paulo: Ed. Avercamp, 2003. 
GOODMAN, G. S. et al. Crianças vítimas no sistema judiciário: como garantir a precisão do testemunho e evitar a revitimização. In: SANTOS, B. R.; GONÇALVES, I. B (Orgs.). Depoimento sem medo (?). Culturas e práticas não-revitimizantes. Uma cartografia das experiências de tomada de depoimento especial de crianças e adolescentes. Brasília: Secretaria Especial dos Direitos Humanos. São Paulo: Childhood Brasil (Instituto WCF-Brasil), 2008, p.21-32.

LAKATOS, E. M.; MARCONI, M. A. Fundamentos de metodologia científica. 6.ed. São Paulo: Ed. Atlas, 2007.

LEITE, M. L. M. A infância no século XIX segundo memórias e livros de viagem. In: FREITAS, M. C. (Org.). História social da infância no Brasil. 2.ed. São Paulo: Ed. Cortez, 1999.

ORGANIZAÇÃO DAS NAÇÕES UNIDAS. Convenção dos Direitos da Criança. 1989. Disponível em: <http://www.unicef.org/brazil/pt/resources_10120. htm>. Acesso em: 17 set. 2013.

CFESS. Reflexões ético-políticas sobre a Metodologia "Depoimento sem Dano" (DSD) junto a crianças e adolescentes vítimas de violência, abuso ou exploração sexual. Brasília: Conselho Federal de Serviço Social, s/d. 22p. Disponível em: <http:// http://www.cfess.org.br/arquivos/Documento_ DSD_COFI.pdf>. Acesso em: 04 out. 2013.

RIZZINI, I; RIZZINI, I. A institucionalização de crianças no Brasil: percurso histórico e desafios do presente. Rio de Janeiro: Ed. Puc-Rio; São Paulo: Loyola, 2004.

ROZANSKI, C. A. Abuso sexual infantil: denunciar ou silenciar? Buenos Aires: Ed. Argentina S/A, 2003.

SANTOS, B. R.; GONÇALVES, I. B (Orgs.). Catálogo das experiências alternativas de tomada de depoimento especial de crianças e adolescentes no mundo: leitura socioantropológica e quadro sinótico. In: Depoimento sem medo (?). Culturas e práticas não-revitimizantes. Uma cartografia das experiências de tomada de depoimento especial de crianças e adolescentes. Brasília: Secretaria Especial dos Direitos Humanos. São Paulo: Childhood Brasil (Instituto WCF-Brasil), 2008, p. 33-52.

SILVA, I. R. A rede de proteção de crianças e adolescentes envolvidos em situações de violência na perspectiva dos direitos humanos. In: Conselho Federal de Psicologia. Falando sério sobre a escuta de crianças e adolescentes envolvidos em situação de violência e a rede de proteção - Propostas do Conselho Federal de Psicologia. Brasília: Conselho Federal de Psicologia, 2009, p. 17-26.

SOUZA, A. M. Síndrome da alienação parental: um novo tema nos juízos de família. São Paulo: Cortez, 2010.

SOUZA, R. O. Abertura. In: Conselho Federal de Psicologia. A escuta de crianças e adolescentes envolvidos em situação de violência e a rede de proteção. Brasília: CFP, 2010, p. 13-29.

WOLFF, M. P. Parecer: a Participação do Assistente Social na equipe de atuação da metodologia Depoimento Sem Dano (DSD). 2008. Disponível em: <http://www.mpes.gov.br/anexos/centros_apoio/ arquivos/17_21141125471582008_Parecer\%20 favoravel.pdf> Acesso em: 04 out. 2013. 